\title{
Clustering Biotechnology Industry in Scotland and Foreign Direct Investment
}

\author{
NOZAWA Kazuhiro \\ Graduate Student, University of Tokyo, Meguro, Tokyo 153-8902, Japan
}

\begin{abstract}
The biotechnology industry is one of the representative industries of a knowledgebased economy. Many biotechnology clusters have been growing in the world. The Scottish biotechnology cluster has been rapidly growing. It is likely to endogenously develop based on the utilisation of the local universities' knowledge, and a number of indigenous biotechnology-related companies are established in terms of interaction between local actors, such as government, university and companies. One of the characteristics of the Scottish biotechnology industry cluster is to be created by government initiative rather than by market mechanisms. The Scottish government has aggressively induced foreign direct investment into the biotechnology sector due to limitation of local resources. Consequently, a large number of foreign pharmaceutical companies have invested heavily in local biotechnology firms and universities in Scotland. As described in the two case studies, there are a number of collaborative researches between indigenous institutes and external foreign companies in the Scottish biotechnology sector. In the biotechnology sector, innovation is likely to be generated at the nexus of the local and global networks. Thus, the competitive advantage of the region might not be determined by solely local conditions, but global factors also seem to contribute to the enhancement of the local industry. The result provides some lessons to the Japanese industrial cluster plan which has been strongly promoted by government bodies. In addition, policy makers should reconsider the role of FDI as a learning opportunity.
\end{abstract}

Key words: biotechnology, cluster, Scotland, knowledge-based economy, FDI

\section{Introduction}

The creation of an industry cluster draws attention not only to scholars but also policy makers at present. In fact, the Japanese Government, the Ministry of Economy, Trade and Industry (METI), has been promoting the Industrial Cluster Plan since 2001. Ishikura et al. (2003) and her colleague introduce cluster theory and cases of industrial clusters. Yamazaki (2005), co-author of Ishikura et al. (2003), scrutinises the Industrial Cluster Policy by METI. Also Yamamoto (2004) criticises the explanations of cluster theory which Ishikura and her colleague explain. Ishikura and other scholars describe cluster theory based on Porter's study (1990, 1998). Actually, the Japanese Government's industrial cluster policy depends on Porter's ides.
Porter (1990,1998) analysed a large number of local economies, and identified the conditions for a strong local economy, which he defined as a 'cluster'. Porter $(1990,1998)$ analyses the industrial agglomeration phenomenon, and develops his concept of the "cluster" by which he (Porter 1990) induces the competitive advantage of a nation's industries.

Porter (1998: 214-220) explains that factors in the formation of clusters depend on local elements, which are 1) reduction of transaction costs, 2) formation of a labour market, 3) share of information, 4) spill-over effects, and 5) access to business support. However, obviously, business does not depend solely on local factors. Firms in a cluster trade with outside partners, and procure goods, money or staff beyond the border of the cluster. An industrial cluster is certainly constituted not only by indigenous elements but also by external ones. 
Recently, many researchers (Lundvall 1992; Gibbons et al. 1994; Florida 1995; Nonaka and Takeuchi 1995; Etzkowitz and Leydesdorff 1997; Cooke 2002a) have drawn attention to knowledge as an economic resource. In order to convert knowledge into economic profits, government bodies constructed an institutional infrastructure for technology transfer. Because of the increasing role of knowledge as an industrial resource, universities have been recognised as an economic engine in a region (Etzkowitz and Leydesdorff 1997: 1; Charles 2003). Because the interactions between university and industry scarcely happen by chance, government should stimulate this relationship in terms of setting rules or providing incentives (Etzkowitz and Leydesdorff 1997: 2). These institutional interactions among university, industry and government are likely to contribute heavily to regional economic development. Etzkowitz and Leydesdorff (1997: 1) name the relationships among university-industry-government as a "Triple Helix". This relation is considered as a critical institutional infrastructure of a knowledgebased economy. Since institutional interactions require propinquity, the system of the knowledge-based economy is a highly localised matter (Malmberg and Power 2004). This notion does not contradict cluster theory; rather it has an affinity with it (Cooke 2002a: 7, 122). Both cluster theory and the theory of the knowledgebased economy stress the importance of social interaction, and both are considerably local systems. In fact, Porter (1998: 208) argues that a "knowledge-based economy creates a far more textured role for clusters". Thus, clusters under the knowledge-based economy are constituted with broadly local-institutional networks which are involved with universities or research institutes.

A variety of scholars (Gibbons et al. 1994; Cooke 2002a; Asheim and Isaksen 2002) insist that proximate relationship is important to the generation of knowledge. On the other hand, several researchers (Malmberg 2003; Bathelt et al. 2004; Wolfe and Gerrtler 2004; Simmie 2004) maintain the importance of global networks in the generation of knowledge. Simmie (2004) suggests that innovation is stimulated by means of access to multiple channels around the world, and innovative activity does not always depend on localised associations. Knowledge transactions have been openly carried out across borders. Bathelt et al. (2004) argue that it is necessary to create a new knowledge fusion of close and distant interactions. In their notion internal networks are stimulated to share and combine knowledge resources at the same time knowledge is transacted through external networks. Bathelt et al. (2004) express this dimension as a combination of 'local buzz' and 'global pipeline'.

In this situation, the Scottish Executive emphasises to create more distinctive and more value-added industries utilising knowledge (Scottish Executive 2001a, 2001b). Scotland in particular has been actively promoting an industrial policy which aims to create knowledge-intensive industries. As a representative of a knowledge intensive industry, the Scottish government has attempted to endogenously develop biotechnology industry clusters. As a consequence, an agglomeration of the biotechnology industry emerged in Scotland.

As regards Scottish industry, DTI (1999), Cooke (2002a), Peters and Hood (2002) and Leibovitz (2004) examined the Scottish biotechnology industry. However, they focus not on influences of external factors but influences of local factors in the biotechnology sector. In terms of highlighting the implications of external factors in the cluster, the research would unveil some significant characteristics of the Scottish biotechnology industry cluster. Therefore, the research question is set as how, and to what extent, foreign direct investment (FDI) has contributed to the creation of the biotechnology industry cluster in Scotland. Therefore, the purpose of the research is to reveal characteristics of the Scottish biotechnology industry cluster and the implication of foreign investment in its formation.

The Scottish biotechnology industry cluster is complex to describe holistically. Hence, a case study approach is adopted for the research. We examine an example of the geographical agglomeration of biotechnology-related activity in Dundee as a case study. The Dundee case study demonstrates the agglomeration of territorial relationships among biotechnology-related sectors and illustrates the process of globalisation 
of indigenous organisations. In addition, Japanese pharmaceutical companies are one of the major foreign investors in the Scottish biotechnology industry. We illustrate the Japanese investors' implications for the Scottish biotechnology sector and how collaborative research can overcome geographical and cultural gaps as another case study. On the one hand, the Dundee case covers the demand side of foreign investment in a local place. On the other hand, the Japanese investor's case deals with the supply side of the investment. The dual-case study unveils some of the interactions between local environment and global factors. In this research, data was gathered by library work and interviews. 13 interviews were held to staff of local government, business promotion, venture companies and university in the Scottish biotechnology sector from May 2004 to July 2004.

The formation of the biotechnology industry cluster in Scotland is worth investigating because Scottish industrial policy appears to be a good model of the creation of a knowledge-intensive cluster by a government-led approach. Specially, Japanese cluster approach has been promoted by the central government's and local government's initiatives. The research could assist us to further understand the regional economic develop- ment policy. At the same time, the survey of the impact of foreign investment could reveal the resulting benefits and problems for the cluster. The findings of the survey should provide some lessons about how foreign investments influence the knowledge-based cluster.

\section{The Scottish Biotechnology Industry}

Scotland has traditionally had a good reputation for biology and medicine in the academic field. In fact, the Roslin Institute announced the success of the production of a cloned sheep named "Dolly" in 1997. Because it was the world's first cloned mammal, the news astonished the world. Drawing upon a survey by Scottish Enterprise (2003), Figure 1 shows the numbers of organisations and workers in the biotechnology sector in Scotland. Figure1 indicates that the total number of biotechnology-related organisations went up from 257 to 513 from 1999 to 2003. Moreover, the number of jobs also increased from 12,729 to 26,324 in four years. In short, the Scottish biotechnology industry has been rapidly doubling its volume in four years. Biotechnology-related companies are geographically concentrated in three cities, Edinburgh, Glasgow and Dundee. In 2002 the number of

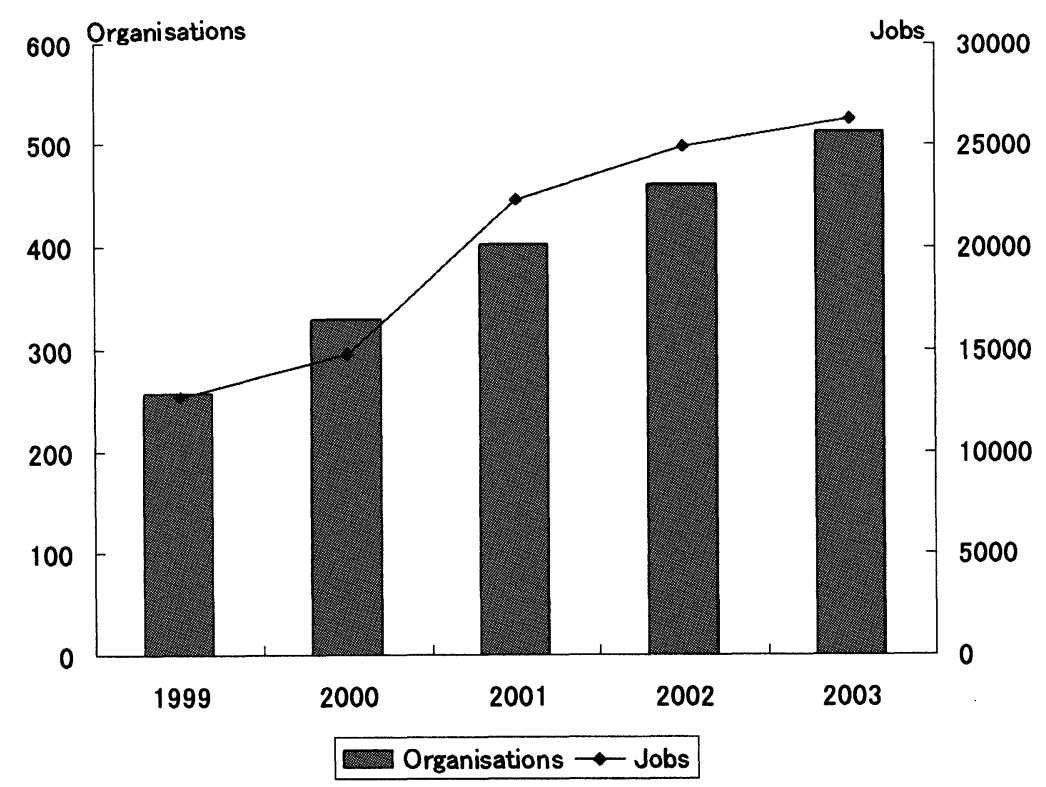

Figure 1. Number of biotechnology-related organisations and jobs in Scotland. Source: Scottish Enterprise 2004. 


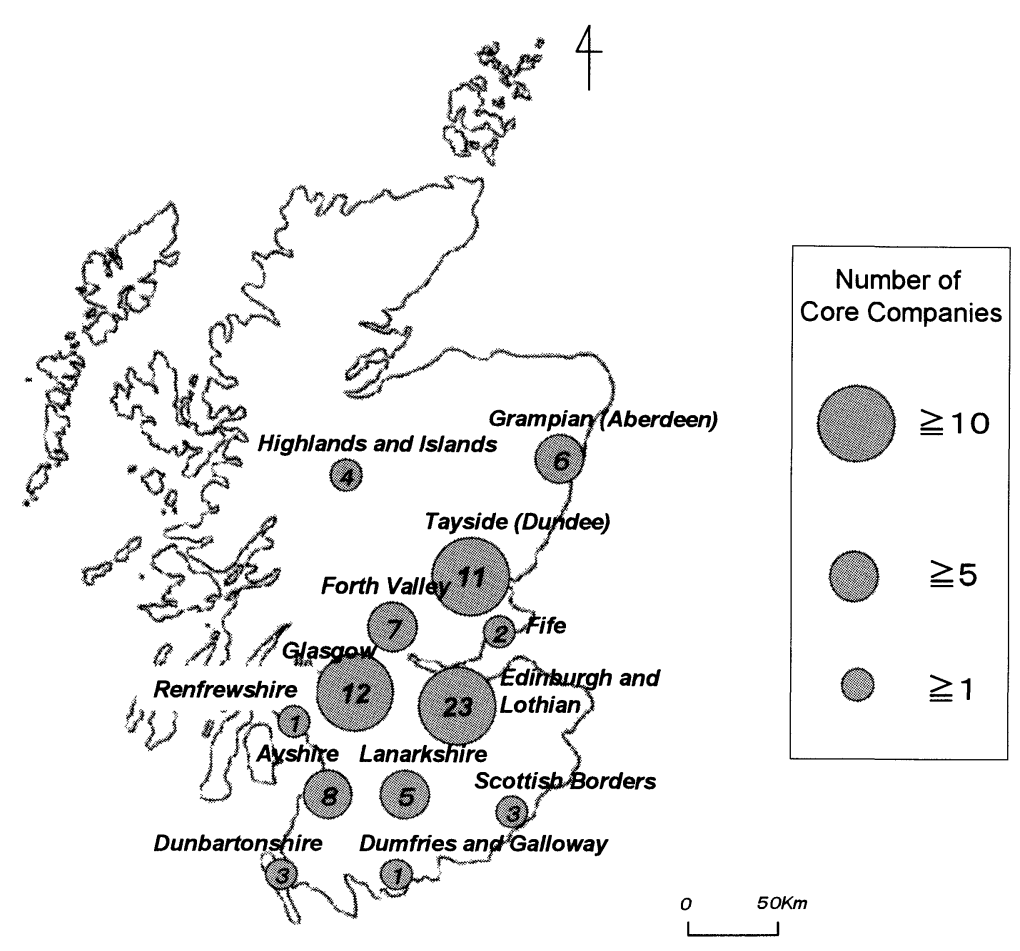

Figure 2. Area location of biotechnology-core companies in Scotland in 2002. Source: Scottish Enterprise 2003.

core companies $^{1}$ in each city was: Edinburgh and surrounds, 23; Glasgow, 12; and Dundee and surrounds, 11 (see Figure 2). ${ }^{2}$

The Scottish government has been strongly promoting the life science industry. The government has prioritised the biotechnology industry as one of four pilot clusters ${ }^{3}$ since 1997 because of the existence of scientific excellence in the region and its potential growth. A number of biotechnology companies have been established every year. Most of them are spin-offs from local research institutes such as universities or the NHS (National Health Services). Although local universities have been a significant contributor to the creation of the biotechnology industry, one of the distinctive characteristics of the biotechnology cluster in Scotland is the government's strong leadership, especially through Scottish Enterprise ${ }^{4}$ (SE) (DTI 1999; Cooke 2001a; Peters and Hood 2002; Leibovitz 2004). Some interviewees praised the contribution of $\mathrm{SE}$ to the biotechnology industry. SE has facilitated the commercialisation of research, provided opportunities for training for workers, introduced alliance companies, and invested public capital in the biotechnology sector and so on. $\mathrm{SE}$ has been the predominant catalyst in the development of this sector. Nevertheless, despite the fact that many biotechnology companies are indigenous, the interactions among them are weak. Furthermore, because private finance is not plentiful in Scotland, public funds underpin the sector. In other words, the local private sector is too small and fragile to grow for itself without the government's support. Therefore the government should stimulate local business activity in order to facilitate the growth of the biotechnology sector. The Scottish biotechnology industry cluster seems to have been created by government initiative rather than market mechanisms (Cooke 2002b).

In spite of the government's efforts, the Scottish biotechnology cluster has been recognised as 'embryonic' (DTI 1999: Leibovitz 2004). There are a couple of significant reasons why the Scottish biotechnology cluster is still embryonic. First, this industry is relatively young and lags behind other biotechnology clusters in the USA 
or Cambridge (DTI 1999; Cooke 2001a). Although Scotland is historically renowned for academic excellence in biotechnology or medicine, commercial utilisation of the technology was not active (Scottish Executive 1999). Second, the number of local companies is not enough to achieve critical mass due to the weakness of entrepreneurship in comparison with the US or Cambridge (Cooke 2001a). In addition, bio-related vertical business integrations in the region are weak. Third, there is not sufficient financial resource in the cluster. The biotechnology sector is a capital-intensive industry and the development of research depends on access to finance. In short, the Scottish biotechnology cluster is not strong enough to be self-sustaining at the moment. The cluster requires the government's intervention and external resources in order to further develop.

\section{Implications of Foreign Investment}

The Scottish Executive has placed an emphasis on the global linkage of industries, and the biotechnology industry is not an exception. The government's biotechnology strategy (Scottish Enterprise 2003) emphasises the importance of the international network to the biotechnology industry. In fact, the government, especially Scottish Development International (SDI), has been attracting foreign investment for the biotechnology sector as well as other industries.
The government's goal for foreign investment is to upgrade local firms and technology and to increase spin-off activity in terms of linkage of foreign factors with indigenous institutions (Scottish Executive 2000, 2001c). SE and SDI powerfully assist the development of global enterprise networks. Hence, as a result of substantial assistance from the government, a large number of foreign firms have invested in the Scottish biotechnology industry. Table 1 presents the amount of foreign investment, the number of projects and related jobs in the biotechnology sector. Foreign investors have annually invested hundreds of millions of pounds in more than 50 projects in the Scottish biotechnology sector. During 2000-2001 more than one billion pounds was invested. In each geographical unit of investors, Europe has been constantly contributing to the sector. However, North America was a huge contributor to investment in the Scottish biotechnology sector, and its share of total cumulative amount of investment from 1998 to 2003 was approximately $60 \%$.

Venture capital firms and pharmaceutical companies are two dominant players in foreign investment. In general, venture capital firms aim to acquire capital gain as a result of internal public offering (IPO). The purpose of pharmaceutical companies as an investor is to access novel knowledge or technology, making alliances with biotechnology firms or universities. A large number of pharmaceutical companies have invested

Table 1. Amount of foreign investment and number of its project and jobs in the Scottish biotechnology sector

\begin{tabular}{|c|c|c|c|c|c|c|}
\hline & & 1998-1999 & $1999-2000$ & 2000-2001 & $2001-2002$ & 2002-2003 \\
\hline \multirow[t]{3}{*}{ Asia } & Number of Projects & 6 & 6 & 12 & 9 & 4 \\
\hline & Planned Investment (£m) & 135.0 & 44.9 & 102.0 & 61.5 & 5.6 \\
\hline & Number of Planned Jobs & 2,639 & 630 & 835 & 850 & 105 \\
\hline \multirow{3}{*}{$\begin{array}{l}\text { Europe } \\
\text { (Including UK) }\end{array}$} & Number of Projects & 43 & 46 & 38 & 29 & 35 \\
\hline & Planned Investment (£m) & 481.4 & 238.8 & 138.9 & 130.0 & 144.1 \\
\hline & Number of Planned Jobs & 5,199 & 8,693 & 5,014 & 3,373 & 4,883 \\
\hline \multirow[t]{3}{*}{ North America } & Number of Projects & 29 & 39 & 52 & 21 & 18 \\
\hline & Planned Investment (£m) & 144.9 & 366.5 & $1,522.3$ & 79.8 & 55.3 \\
\hline & Number of Planned Jobs & 3,029 & 10,011 & 8,497 & 2,163 & 2,171 \\
\hline \multirow[t]{3}{*}{ Total } & Number of Projects & 78 & 91 & 102 & 59 & 57 \\
\hline & Planned Investment ( $£$ ) & 761.3 & 650.2 & $1,763.2$ & 271.3 & 205.0 \\
\hline & Number of Planned Jobs & 10,867 & 19,334 & 14,346 & 6,386 & 7,159 \\
\hline
\end{tabular}

Source: Scottish Development International unpublished document. 
in the biotechnology industry in Scotland as well as in other clusters.

The government has aggressively induced foreign investment into the biotechnology sector. Consequently, foreign companies have invested heavily in local biotechnology firms or universities. There are a number of collaborative researches between indigenous institutes and foreign companies in the Scottish biotechnology sector. Foreign investment seems to be indispensable for the growth of the sector. It is certain that foreign investment to some extent contributes to the growth of the local economy. However, the aim of investment for multinational pharmaceutical companies is to access new knowledge or technology. New knowledge as a result of collaboration is likely to be taken outside of Scotland. The characteristics of foreign investment in the biotechnology industry have both benefits and problems for Scotland. The following case studies will explain why and how foreign investment has influenced the Scottish biotechnology sector.

\section{Case Studies}

\section{Dundee phenomenon}

Dundee, located approximately 60 miles north of Edinburgh, is the fourth largest city in Scotland. In 2001 its population was about 145,000. Dundee had thrived on shipbuilding and textile (jute) industries in the 19th century. ${ }^{5}$ Both the shipbuilding and textile sectors were devastated after the Second World War because of a failure to modernise the industries and by global competition. The local economy has been stagnating since then. Hence Dundee City Council has endeavoured to foster new industries. By means of utilising Dundee University as a knowledge centre, the region has made efforts to create a biotechnology cluster.

Dundee has a good reputation as a hub of the biotechnology industry in Scotland at present. Some agglomeration of biotechnology-related organisations in Dundee is observed and the industry has been growing. The number of biotechnology core companies went up from 11 to 25 , and the number of workers increased from 3,500 to 3,800 from 2002 to 2004. In addition, there were 17 medical device companies and 24 support companies in $2004 .^{6}$

The University of Dundee is obviously a significant contributor to the Dundee biotechnology industry. In the biotechnology field the university is renowned as a centre of excellence not only in the UK but also in the world. According to a survey by the Institute for Scientific Information in Philadelphia the university was evaluated as the second best European university in Molecular Biology and Genetics. ${ }^{7}$ Especially, cancer and diabetes research are great strengths of the university. The university launched a $\$ 25$ million new drug discovery project, Division of Single Transduction Therapy. ${ }^{8}$ In addition, seven spinoff biotechnology companies have been established by researchers or graduates of the university. ${ }^{9}$ For instance Cyclacel and CXR Biosciences are famous as establishments by star scientists of the university.

The UK government has been heavily funding researches in life science and promoting and encouraging the biotechnology industry. The Scottish government also has employed several policies for building on success. For example, these policies are building research excellence, commercialising research, growing life sciences business, helping companies access finance, going global market, promoting skills and learning, and strengthening national and international networks (Scottish Enterprise 2003).

At the same time, local government bodies, such as Dundee City Council and Scottish Enterprise Tayside, have been supporting the Dundee biotechnology industry cluster. SE Tayside especially promotes a wide range of supportive activities. In detail, the actions of SE Tayside are as follows. 1) Spin off management: 2) Coordination of meeting person to person: 3 ) Setting up regular meeting or conference: 4) Supporting research or business projects: 5) Marketing: and 6) Investing seed fund in venture companies and universities. ${ }^{10}$ Meanwhile, cooperating with SE Tayside, Dundee City Council has been also forcefully promoting the Dundee biotechnology sector by developing infrastructures such as business park, improving the image and perception of Dundee and attracting inward investment. ${ }^{11}$ Furthermore, the city council invited the establishment of ITI Life Sciences ${ }^{12}$ 

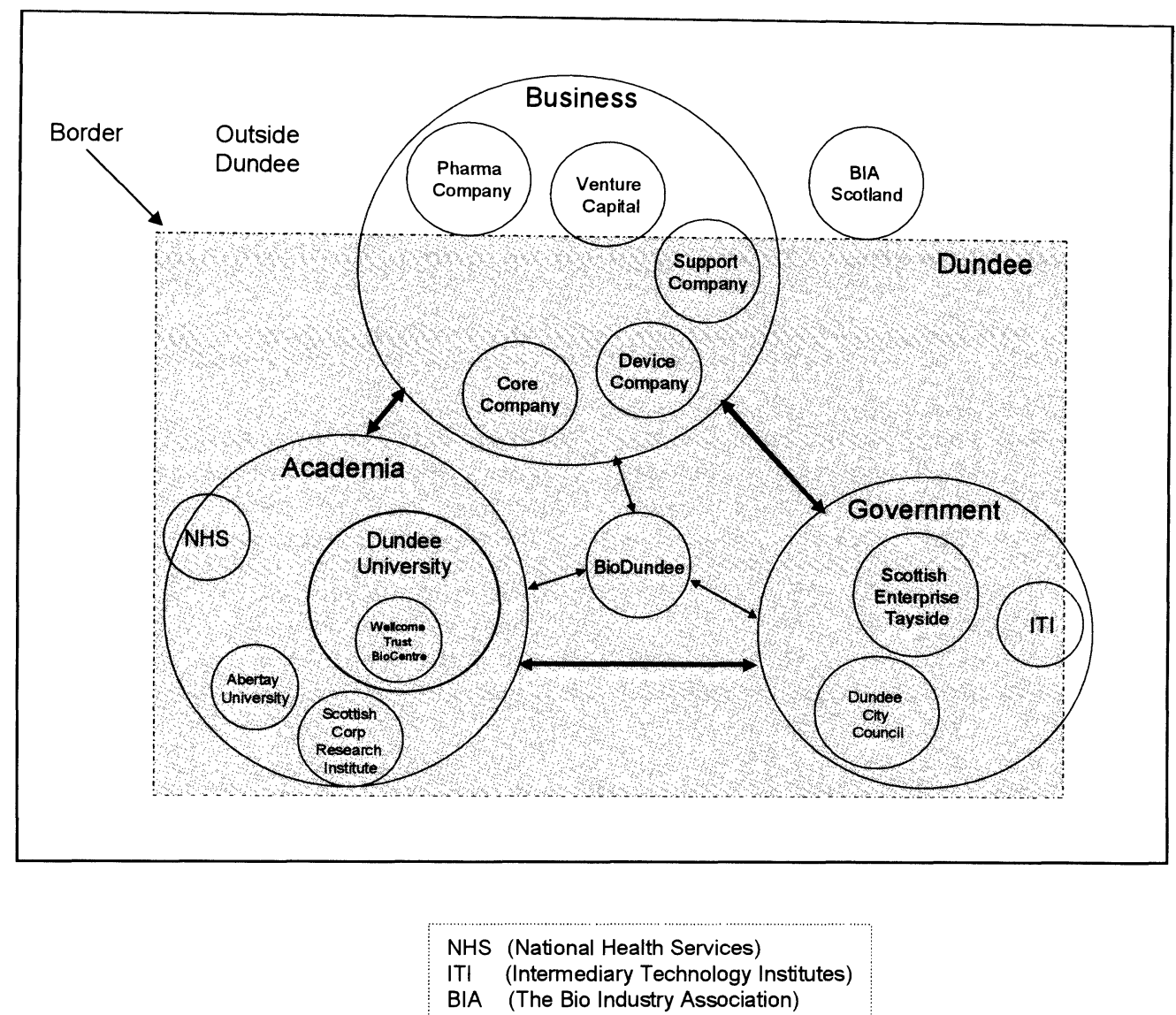

Figure 3. Organisations of Dundee biotechnology cluster.

in Dundee in order to stimulate Dundee's biotechnology business community. BioDundee, a local business partnership was set up between $\mathrm{SE}$, the City Council, universities and local business. ${ }^{13}$ The main aim of BioDundee is to improve the industry's competitiveness through marketing activity by providing information or assisting business opportunities to members. At this point, 45 companies and institutions have joined the organisation. Through these efforts SE Tayside and Dundee City Council have created a local biotechnology business community.

Figure 3 illustrates relationships of the Dundee biotechnology cluster. As interviewees insist, the University of Dundee is a core entity of the cluster because the initiation of the cluster drew on the utilisation of the university's knowledge. Furthermore the university itself has promoted licensing and commercialisation of scientific knowledge and has supported spin-off activity, the local government body has also aggressively backed-up and stimulated entrepreneurship and research. As a result of these efforts, there is an agglomeration of a number of biotechnologyrelated venture firms and support institutions in Dundee. Local biotechnology-related institutions have multiple interactions with academia, government and business. We can clearly see a "Triple Helix" (Etzkowitz and Leydesdirff 1997) in Dundee as well.

These many biotechnology venture firms are obviously indigenous companies; that is, spin-offs from the local university or institute. However, each indigenous biotechnology company is involved in international relationships as well. The situation is demonstrated in the cases of local biotechnology venture firms, CXR Biosciences and Cyclacel.

Professor Roland Wolf and Dr Cliff Elcombe of Dundee University established CXR Biosciences 
Table 2. Nationality of investors of Cyclacel

\begin{tabular}{l|ccccccc}
\hline & UK & Singapore & France & USA & Canada & Japan & Others \\
\hline Venture Capital & 10 & 3 & 2 & 1 & 1 & 1 & 5 \\
Pharmaceuticals & 2 & & 1 & 1 & 1 & & \\
Univeersity & 3 & & & & & \\
\hline
\end{tabular}

Source: Cyclacel HP.

which employs over 30 people, to accelerate drug development, in 2001. In January 2002 the Company started its business with $£ 4$ million funds from Scottish or UK resources. In November 2002 Schering Plough (US) invested $£ 375,000$ in a collaborative research programme with CXR Biosciences and Roslin Institute. In March 2003 CXR Biosciences contracted a license agreement with Pfizer (US), and an undisclosed multinational company. In December 2003 Guerbert (France) agreed to collaborative research for drug discovery. ${ }^{14}$ Thus although CXR Biosciences was started with UK funds, the company has gained global elements in terms of acceptance of foreign investments for collaborative research.

Professor David Lane of Dundee University founded Cyclacel, which employs over 80 people, in 1996. The strength of the firm is to develop molecular drugs for cancer. Cyclacel is a relatively larger and more mature company than CXR Biosciences. The amount of funds has gradually increased over four stages. In 1997 Merlin Fund (UK) invested $£ 2.5$ million as an operational fund. The company gained additional capital of $£ 9.3$ million in $1999, £ 34.3$ million in 2001 and $£ 21$ million in 2004 through new investors. 26 venture capital firms and three UK universities have invested in the company to date. ${ }^{15}$ The breakdown of the nationalities of venture capital firms is shown in Table 2. ${ }^{16}$ In addition, like CXR Biosciences, the company has collaborated with several multinational pharmaceutical companies. ${ }^{17}$ For instance, Cyclacel contracted with Sankyo (Present Daiichi-Sankyo) for the development of anti cancer drugs in December 2003. Sankyo provided research product on phase one, and Cyclacel has been promoting clinical development of oncology drugs. As a result of this collaboration, Cyclacel acquired exclusive right of new drugs, and Sankyo also has the right to sell the new drugs in Japan. ${ }^{18}$ Thus, in spite of the fact that Cyclacel is clearly an indigenous company, the company has opened its arms to the world, and it seems to depend on foreign capital in order to enlarge its business.

The number of firms in the biotechnology sector is progressively increasing at the moment in Dundee. However, most of the firms are newborn and small, and they definitely need government assistance in order to survive in the intensive global competition. As many interviewees stressed, the most critical issue of development of biotechnology business and research was the acquisition of finance. Not only biotechnology ventures but also the university have rushed to acquire finance in order to develop the biotechnology industry. Government bodies have also been assisting powerfully to find funding for the biotechnology-related sector. Nevertheless, financial resources or the opportunity for commercialisation is fairly limited in Dundee as well as in Scotland, so local business or research cannot develop without external resources.

\section{Japanese Investors}

Sankyo (present Daiichi-Sankyo) which collaborated with Cyclacel in Dundee, and other Japanese pharmaceutical companies, have also invested in the Scottish biotechnological companies or research institutes. For instance, Fujisawa (present Astellas) has invested several millions pounds in neuroscience research at Edinburgh University in order to develop novel drugs for treatment of brain diseases such as schizophrenia, stroke and Alzheimer's since 1987. ${ }^{19} \mathrm{Fu}$ jisawa also carried out collaborative research with Strakan, a Scottish biotechnology venture firm, and consequently Fujisawa supplied a new drug to the market. ${ }^{20}$ Mitsubishi Pharmaceutical has invested in 'YRING', a collaborative research project with Glasgow University and Strathclyde University, for development of new anti-psy- 
chotic treatments for schizophrenia since 1997. Kyorin made a first $£ 5.2$ million contract in 2000 and a second $£ 5$ million contract in 2002 with Scottish Biomedical, a biotechnology venture firm, for joint research to discover new drugs to treat patients with diabetes. ${ }^{21}$ The principle feature of Japanese investors to the Scottish bioscience sector is not to invest in factories or $R \& D$ facilities, but a desire for collaborative research with biotechnology firms or universities.

In general, reasons why multinational pharmaceutical companies including Japanese pharmaceuticals invest in foreign biotechnology firms or universities are as follows. 1) Shortage of patents; many multinational pharmaceutical companies face a shortage of new drugs at the present (Cooke 2004): 2) Intensive global competition (Bartholomew 1997; Powell 1998; Ernst \& Young 2003; Roijakkers and Hagedoorn 2003): 3) Technological revolution and multi-disciplinary industry (Oakey et al. 1990; Zucker and Darby 1997; Roijakkers and Hagedoorn 2003): 4) Efficiency of R\&D (Gibbons et al. 1994: 49-50). Japanese companies especially emphasised that the purposes of investment in Scotland R\&D were to increase efficiency of $R \& D$, and to access brand-new information. ${ }^{22}$

For the above reasons, Japanese pharmaceutical firms invest in companies or research institutes around the world. A couple of interviewees commented on the strengths of investment in the Scottish biotechnology sector, which are 1) existence of centres of excellence, 2) the government's powerful support, 3) well-educated workers and 4) a stable economic environment. Although consequently multinational pharmaceutical companies would gain some benefits that lead to the reduction of research costs or improved competitiveness, at the same time, there are many risks. First, it is surely high risk to invest in uncertain technology (Roijakkers and Hagedoorn 2003). There is no guarantee of successful development of a new drug. Second, collaborative research could lead to a dependency of basic research on contracted biotechnology research units, weakening the R\&D ability of the firm. In fact, one of the Japanese pharmaceutical companies was outsourcing its basic research, and depended heavily on a Scottish partner.

Japan is far away from Scotland geographically and culturally, and it might be assumed that there would be a huge gap between a Japanese company and Scottish institute. It might be difficult to interact with a research partner. If, as many researchers emphasise (Asheim and Cooke 1998; Cooke 2002a: 107, 2002b; Audretsch 2000; Malmberg and Power 2004), innovative knowledge is only created within proximate and local communities, and if "knowledge openness is caused by some shared history" (Foray 1997), it would be impossible to generate innovative ideas through the interaction between Japanese firms and Scottish organisations. However, both Japanese and Scottish organisations have made efforts to overcome this distance. Firstly, both Scottish and Japanese collaborators have regular and frequent meetings every year. ${ }^{23}$ A Scottish interviewee actually visited Japan seven times within 18 months. The meetings were usually held in Scotland, Japan or the European headquarters of a Japanese pharmaceutical company. Both collaborators pay attention to clarity and transparency in their communication. ${ }^{24}$ Secondly, they have exchanged researchers with each other. The time period of staying in each research laboratory is from a week to a couple of years. ${ }^{25}$ Japanese researchers gain brand-new academic information ${ }^{26}$ whilst Scottish researchers obtain commercial experience. Thus, in terms of exchanging ideas or experience both sides have tried to stimulate research and maximise their benefits, based on a contract. It is certain that the contract is a vital tool to combine each far distant entity. Because it is difficult to establish relationships among distant partners, some sort of investment seems to be necessary for interactions (Malmberg 2003; Bathelt et al. 2004). No interviewee ${ }^{27}$ identified a cultural gap between Japan and Scotland in the research.

The main aim of Japanese investors is not to construct manufacturing or R\&D facilities in the region but to access new knowledge or innovative ideas. However, Japanese investment to some extent contributes to the development of the Scottish biotechnology sector. It definitely stimulates local research activity, and increases jobs. Meanwhile Japanese biotechnology firms gain the fruits of collaborative research by sharing intellectual property rights. It seems to be a reciprocal and symbiotic relationship. 


\section{Conclusion}

In the Scottish biotechnology cluster the numbers of firms and employees have been rapidly growing. It appears to be an endogenous development which utilises the knowledge of local universities and established indigenous companies and is powerfully supported by local government. Furthermore, like Dundee, local biotechnology-related networks are also expanding in Edinburgh or Glasgow, and similar biotechnology industry clusters can be seen there (Leibovitz 2004). The Scottish biotechnology cluster appears to be a complex of a couple of sub-clusters. Local institutions such as government, academia and business, interacted determinedly with each other to develop the biotechnology sector. As Etzkowitz and Leydesdorff (1997) indicate, by means of the efforts of the Scottish government, a 'thick' local institutional interaction, a "Triple Helix", emerged in Scotland.

However, the cluster is far from critical mass and not self-sufficient (DTI 1999; Peters and Hood 2002; Leibovitz 2004). Despite the fact that there are biotechnology-related communities, local business transactions seem to be relatively weak among indigenous biotechnology firms (Leibovitz 2004). Rather, the companies have been aggressively interacting with global companies in search of an opportunity for the commercialisation of technology. Solely local resources are not enough to develop their business, so biotechnology firms must access the world. On the contrary, not only Japanese investors but also other foreign investors have been seeking for the seeds of new drugs. In order to access innovative knowledge, multinational pharmaceutical companies have invested in local biotechnology ventures or research laboratories. Multi National Companies (MNCs) tend to invest in limited term projects rather than properties. Foreign investment in the biotechnology industry has influenced the Scottish economy because the amount of foreign investment has reached hundreds of millions of pounds, and it has certainly created jobs. Companies or universities can hire expertise and graduates. Consequently, foreign investment appears to contribute to the gain and retention of knowledge in Scotland.

The Scottish government's biotechnology strategy emphasised the importance of international networks of the biotechnology industry (Scottish Enterprise 2003). The government has been promoting foreign investment in the biotechnology sector. The government set the aims of foreign investment as upgrading local firms and technology and increasing spin-off activity in terms of the linkage of foreign factors with indigenous institutions (Scottish Executive 2000, 2001c; Raines and Brown 2001). SE and SDI have powerfully assisted in achieving the global enterprise networks in the Scottish biotechnology sector.

Thus the Scottish biotechnology cluster has active local interactions, but at the same time it has a high dependency on global resources. In short, it might be said that the Scottish biotechnology cluster is not only a nexus of domestically untraded interdependencies (Storper 1995) but also a focal point of internationally traded interdependencies (Bartholomew 1997).

The Scottish biotechnology industry cluster seems to be somewhat inconsistent with Porter's cluster theory. In fact, local institutions such as government, university and business, are frequently associated with each other, and we recognise a sort of agglomeration of biotechnology-related activities in Scotland. However, there is not a sufficient local business value chain in the Scottish biotechnology cluster. In Porter's argument (1998: 213), geographical proximity would enhance some local economic conditions such as productivity, innovation and creation of new business. However, the transactions of the Scottish biotechnology sector extended beyond the cluster.

There are a couple of reasons why the Scottish biotechnology sector positively transacted with external partners. Firstly, as already noted, the sector has not yet reached critical mass which means that there are not enough local customers, rivals, or financial resources to be self-sufficient (DTI 1999). Secondly, the biotechnology industry intrinsically included an international aspect (Powell et al. 1996; Gertler and Levitte 2003). For instance, collaborative research alliances between multinational pharmaceutical firms and biotechnology venture firms or institutes are a common phenomenon (Ernst 
\&Young 2003) because MNCs must seek new technology in order to survive (Bathelt et al. 2004) while biotechnology venture firms need finance to develop their business. As described in the two case studies, the Scottish biotechnology sector, both biotechnology venture firms and research institutes, were engaged with external multinational pharmaceutical companies in joint researches. Cross-border collaborative research enables organisations to enhance their capability for innovation in terms of access to a wider range of solutions to technological problems (Bartholomew 1997). International R\&D activity seems to be an important source of competitive advantage for companies. Hence, researchers or business promoters need to widen contacts with various sources.

Thirdly, the biotechnology academia is also an international and open community. Scientists tend to communicate and exchange knowledge beyond their borders. Therefore, in order to generate innovation, external knowledge networks should be required because "in the new competitive regime, commercial success requires the ability to generate knowledge using resources which are not stored in-house but distributed throughout a vast and increasingly global network" (Gibbons et al. 1994: 50). Thus, because the biotechnology industry has been created by a large number of academic researchers who have an open attitude to communicate with externality, the sector is also global and open (Oakey et al. 1990: 111).

On the one hand, as indicated earlier, various researchers emphasise (Porter 1998: 221-223; Asheim and Cooke 1998; Cooke 2002a:107, 2002b; Audretsch 2000) that innovative knowledge is created in a proximate and local community. On the other hand, several scholars maintain (Keeble et al. 1998, Asheim and Isaksen 2002, Malmberg 2003, Bathelt et al. 2004, Wolfe and Gertler 2004, Simmie 2004) that the acquisition of external knowledge is a critical matter to facilitate innovation and regional growth, and innovation is generated across borders. It is certain that geographical proximity may help to generate tacit knowledge by means of frequent and flexible communications; at the same time, the input of codified knowledge is also important to the creation of innovative ideas
(Foray 1997). Malmberg (2003) suggests that there are qualitative differences between local networks and global ones. Thus, the critical thing for innovation in the biotechnology sector might be to exploit and link external knowledge with local resources (Oliver 2001, Leibovitz 2004). The combination of local and global knowledge networks significantly contributes to the creation of new ideas and innovation in the biotechnology sector (Gertler and Levitte 2003; Bathelt et al. 2004; Simmie 2004).

In Scotland we observed a variety of knowledge interactions beyond the cluster in order to generate innovative knowledge. Although local conditions are still a vital factor for the regional economic development, the global factors also contribute to the enhancement of competitiveness of the local industry. Innovation is generated at the nexus of the local and global networks. It is important for regions that local and global sources are mixed and synthesised together in order to maximise benefits and minimise risks. Therefore, regional development policy should consider enhancing the operational capacity of the combination between global factors and the local environment. There is some gap between the characteristics of the Scottish biotechnology cluster and the conventional cluster theory. It might possibly result from the idiosyncrasy of a brand-new industry, which is domestic and global network industry. The result provides some lessons to the Japanese industrial cluster plan, which has been strongly promoted by government bodies, based on Porter's cluster theory. In addition, although policy makers of the Japanese industry cluster have been hesitating to attract FDI, they should reconsider the role of FDI as a learning opportunity.

The research succeeded in identifying the characteristics of the Scottish biotechnology industry cluster. Nevertheless, it could not indicate whether it was a common characteristic of the biotechnology cluster. The paper described one sub-cluster's case and one case of foreign involvement, and it did not present the situation in other clusters. Hence it is difficult to identify the general tendencies of the biotechnology cluster from the results. In addition, as noted before, the Scottish biotechnology cluster has been created chiefly by government initiative. The re- 
search could not examine the adoption of the Scottish case to the recent Japanese one. These issues will be scrutinised in the next research.

\section{Acknowledgements}

This paper is based on the master degree dissertation submitted to the University of Newcastle upon Tyne on August 2004. I would like to express my greatest gratitude to my supervisor, Professor John Tomaney. I also wish to thank Professor Hiroshi Matsubara at the University of Tokyo and two anonymous referees for their helpful comments.

(Received 6 June 2007) (Accepted 12 October 2007)

\section{Notes}

1. SE defines Core Company as one "that uses modern biological techniques to develop products or intellectual property applicable to human health care, diagnostics, agro-bio, veterinary or environment. Includes pharmaceutical companies".

2. Scottish Enterprise. 2004. Life Sciences Scotland: Source Book 2004

3. Four pilot clusters are oil and gas, food, semiconductor, and biotechnology.

4. Scottish Enterprise was established in 1991 as a regional development agency by the Scottish local government. The main aim is to develop and implicate a regional economic strategy. Its territorial responsibility is for Lowland Scotland.

5. Local Histories (http://www.localhistories.org/ dundee.html)

6. Source from Scottish Enterprise Tayside.

7. The survey was based on the number of citations in research papers by other scientists from January 1993 to April 2003. Top was University of Geneva, third was UCL, fourth was Cambridge, Fifth was Oxford. (http://www.dundee. ac.uk/pressoffice/contact/2003/september/topuni.html)

8. University of Dundee Division of Cell Signalling is in collaboration with six major pharmaceutical companies, AstraZeneca (UK-Sweden), Boegringer Ingelheim (Germany), GlaxoSmithKline (UK), Merck (USA), Merck KGaA (Germany), and Pfizer (USA). (http://www.dundee.ac.uk/biocentre/SLSBDIV5home.htm)

9. Axis Shield (1982), Cyclacel (1996), Cypex (1999), Polgen (2000), CXR Sciences (2001), Kinasource (2002), Advantagen (2004) (http://www. dundee.ac.uk/research/main/spinout.html)
10. Inteviewees on 4th June expressed these points.

11. Dundee City Council (http://www.dundeecity.gov. $\mathrm{uk} /$ )

12. ITI (Intermediary Technology Institutes) is a marketing organisation established by the Scottish Government for high technology industry in 2003. ITI has three divisions, life sciences, energy, and techmedia.

13. BioDundee (http://www.biodundee.co.uk/index. asp\#TOP)

14. These comments were based on CXR Biosciences' Home page. (http://www.cxrbiosciences.com/content/index.html).

15. Cyclacel (http://www.cyclacel.com/).

16. Cyclacel (http://www.cyclacel.com/).

17. Cyclacel has been collaborating with GlaxoSmithKline(UK), Astrazeneca (UK- Sweden), CV Therapeutics (USA), Lorus Therapeutics (Canada), and Sankyo (Japan). (http://www.cyclacel.com/).

18. Cycacel (http://www.cyclacel.com/cyc/investors/ news/pressreleases/2003/2003-12-05/).

19. University of Edinburgh Fujisawa institute for Neuroscience (the institute was closed in 2006.) (http://www.research-innovation.ed.ac.uk/commercial/expertise/medicine/neuro12.htm).

20. An interviewee on 17th June mentioned it.

21. Kyorin also made another agreement with Scottish Biomedical for development in the areas of allergy and immunology (an interviewee on 8th June commented it.)

22. Kyorin Pharmaceutical (http://www.kyorin-pharm. co.jp/eg/index.html), Fujisawa Pharmaceutical (http://www.fujisawa.co.jp/), Mitsubishi Pharmaceutical (http://www.m-pharma.co.jp/cgi-bin/eindex.cgi).

23. One biotechnology firm held a regular meeting twice per year. Another held six per year.

24. An interviewee on 8th June pointed it out.

25. Not all companies or institutes mutually delegated their researchers to partner's laboratories. It depends on decisions of each company or institution.

26. An interviewee on 8th June mentioned that a Japanese researcher who worked at a lab in a Scottish university gained a $\mathrm{Ph} \mathrm{D}$ as a result of collaborative research.

27. Interviewees on27th May, 8th June, and 17th June denied the difficulties of communication between Scottish researchers and Japanese counter partners.

\section{References}

Asheim, B. T., and Cooke, P. 1998. Localized innova- 
tion networks in a global economy: A comparative analysis of endogenous and exogenous regional development approaches. Comparative Social Research 17: 199-240.

Asheim, B. T., and Isaksen, A. 2002. Regional innovation systems: The integration of local 'sticky' and global 'ubiquitous' knowledge. Journal of Technology Transfer 22:77-86.

Audretsch, D. B. 2000. Knowledge, globalization, and regions: An economist's perspective. In Regions, globalization, and the knowledge-basedeconomy, ed. J. H. Dunning, 63-81.Oxford: Oxford University Press.

Bartholomew, S. 1997. National systems of biotechnology innovation: Complex interdependence in the global system. Journal of International Business Studies 28: 241-266.

Bathelt, H., Malmberg, A., and Maskell, P. 2004. Clusters and knowledge: Local buzz, global pipelines and the process of knowledge creation. Progress in Human Geography 28: 31-56.

Charles, D. 2003. Universities and territorial development: Reshaping the regional role of the UK universities. Local Economy 18: 7-20.

Cooke, P. 2001a. Biotechnology clusters in the UK: Lessons from localisation of commercialisation of science. Small Business Economics 17: 43-59.

Cooke, P. 2002a. Knowledge economies. London: Routledge.

Cooke, P. 2002b. Biotechnology clusters as regional sectoral innovation systems. International Regional Science Review 25: 8-37.

Cooke, P. 2004. The molecular biology revolution and the rise of bioscience megacentres in North America and Europe. Environment and Planning C: Government and Policy 22: 161-177.

DTI. 1998. Our competitive future. London: DTI.

DTI. 1999. Biotechnology clusters. London: DTI.

Ernst \& Young. 2003. Beyond borders: The global biotechnology report 2003. London: Ernst \& Young LLP.

Etkowitz, H., and Leydesdorff, L. eds. 1997. Universities and the global knowledge economy. London: Pinter.

Florida, R. 1995. Toward the learning region. Futures 27: $527-536$

Foray, D. 1997. Generation and distribution of technological knowledge: Incentives, norms and institutions. In Systems of innovation, ed. C. Edquist, London: Pinter.

Gertler, M. S., and Levitte. Y. M. 2005. Local nodes in global networks: The geography of knowledge flows in biotechnology innovation. Industry and Innovation 12: 487-507.
Gibbons, M., Limoges, C., Nowotny, H. Schwartzman, S., Scott, P., and Trow, M. 1994. The new production of knowledge. London: Sage.

Ishikura, Y., Fujita, M., Maeda, N., Kanai, K., and Yamazaki, A. 2003. Nihon no sangyo kurasuta senryaku. Tokyo: Yuhikaku. (J)

Keeble, D., Lawson, C., Smith H. L., Moore, B., and Wilkinson, F. 1998. Internationalisation process, networking and local embeddedness. Small Business Economics 11: 327-342.

Leibovitz, J. 2004. Embryonic knowledge-based clusters and cities: The case of biotechnology in Scotland. Urban Studies 41: 1133-1155.

Lundvall, B. ed. 1992. National systems of innovation. London: Pinter.

Malmberg, A. 2003. Beyond the cluster-local milieus and global connections. In Remaking the global economy, ed. J. Peck and H. Yeung, 145-159. London: Sage.

Malmberg, A., and Power, D. 2005. (How) do (firm in) clusters create knowledge? Industry and Innovation 12: 409-431.

Nonaka, I., and Takeuchi, H. 1995. The knowledge-creating company. Oxford: Oxford University Press.

Oakey, R., Faulkner, W., Cooper, S., and Walsh, V. 1990. New firms in the biotechnology industry: their contribution to innovation and growth. London: Pinter.

Oliver, A. L. 2001. Strategic alliances and the learning life-cycle of biotechnology firms. Organisation Studies 22: 467-489.

Peters, E., and Hood, N. 2002. Scotland biotechnology cluster: Strategic issues and responses. In Scotland in a global Economy. ed. N. Hood. J. Peat. E. Peters. and S. Young, 91-111. London: Palgrave Macmillan.

Porter, M. E. 1990. The competitive advantages of nations. London: Macmillan.

Porter, M.E. 1998. On competition. Boston: Harvard Business School Publishing.

Powell, W. 1998. Learning from collaboration: Knowledge and networks in the biotechnology and pharmaceutical industries. California Management Review 40: 228-240.

Powell, W., Koput, K., and Smith-Doerr, L. 1996. Interorganizational collaboration and the locus of innovation: Networks of learning in biotechnology. Administrative Science Quarterly 31: 116-145.

Raines, P., and Brown, R. 2001. From 'international' to 'global': The Scottish Enterprise global companies strategies and new approaches to overseas expansion. Regional Studies 35: 657-668.

Roijakkers, N., and Hagedoorn, J. 2003. Inter-firm R\&D partnering in high technology industries. In $\mathrm{Al}$ - 
liance capitalism and corporate management, ed. J. H. Dunning. and G. Boyd, 63-90. Cheltenham: Edward Elgar.

Scottish Enterprise. 2003. Life sciences Scotland. framework for action 2003-2004. Glasgow: Scottish Enterprise.

Scottish Enterprise. 2004. Life sciences Scotland: Source book 2004. Glasgow: Scottish Enterprise.

Scottish Executive. 1999. Towards the knowledge economy. Glasgow: Scottish Executive.

Scottish Executive. 2000. The way forward: framework For economic development in Scotland. Edinburgh: Scottish Executive.

Scottish Executive. 2001a. The knowledge economy cross cutting initiative. Edinburgh: Scottish Executive.

Scottish Executive. 2001b. A smart, successful Scotland: Ambition for the Enterprise Networks. Edinburgh: Scottish Executive.

Scottish Executive. 2001c. Scotland: A global connections strategy. Edinburgh: Scottish Executive.

Simmie, J. 2004. Innovation and clustering in the globalised international economy. Urban Studies 41:1095-1112.

Storper, M. 1995. The resurgence of regional economies, ten years later: The region as a nexus of untraded interdependencies. European Urban and Regional Studies 2: 191-221.

Wolfe, D. A., and Gertler, M. S. 2004. Clustering from the inside and out: Local dynamics and global linkages. Urban Studies 41:1071-1093.

Yamamoto, K. 2004. Sangyo kurasuta keikaku no ronri ni kansuru hihanteki kosatsu. Kezai-Shirin 72: 311-336. (J) (Yamamoto, K. 2006. The Industrial Cluster Plan of the Japanese Government and the realities of regional economies in Japan. Raumforschung und Raumordnung 64. Jg., Heft 1: 28-40).

Yamazaki, A. 2005. Nihon no sangyo kurasuta keikaku: Sono haikei to tokushitsu. Annals of the Japan Association of Economic Geographers 51: 499-511. (JE)

Zucker, L. G., and Darby, M.R. 1997. Present at the biotechnology revolution: Transformation of technological identity for a large incumbent pharmaceutical firm. Research Policy 26: 429-446.

$(\mathrm{J})$ : written in Japanese

(JE): written in Japanese with English abstract 